\title{
Interação solo-estrutura em galpões metálicos treliçados com cobertura em arco circular
}

\author{
Soil-structure interaction in steel truss sheds roofed by \\ circular arches
}

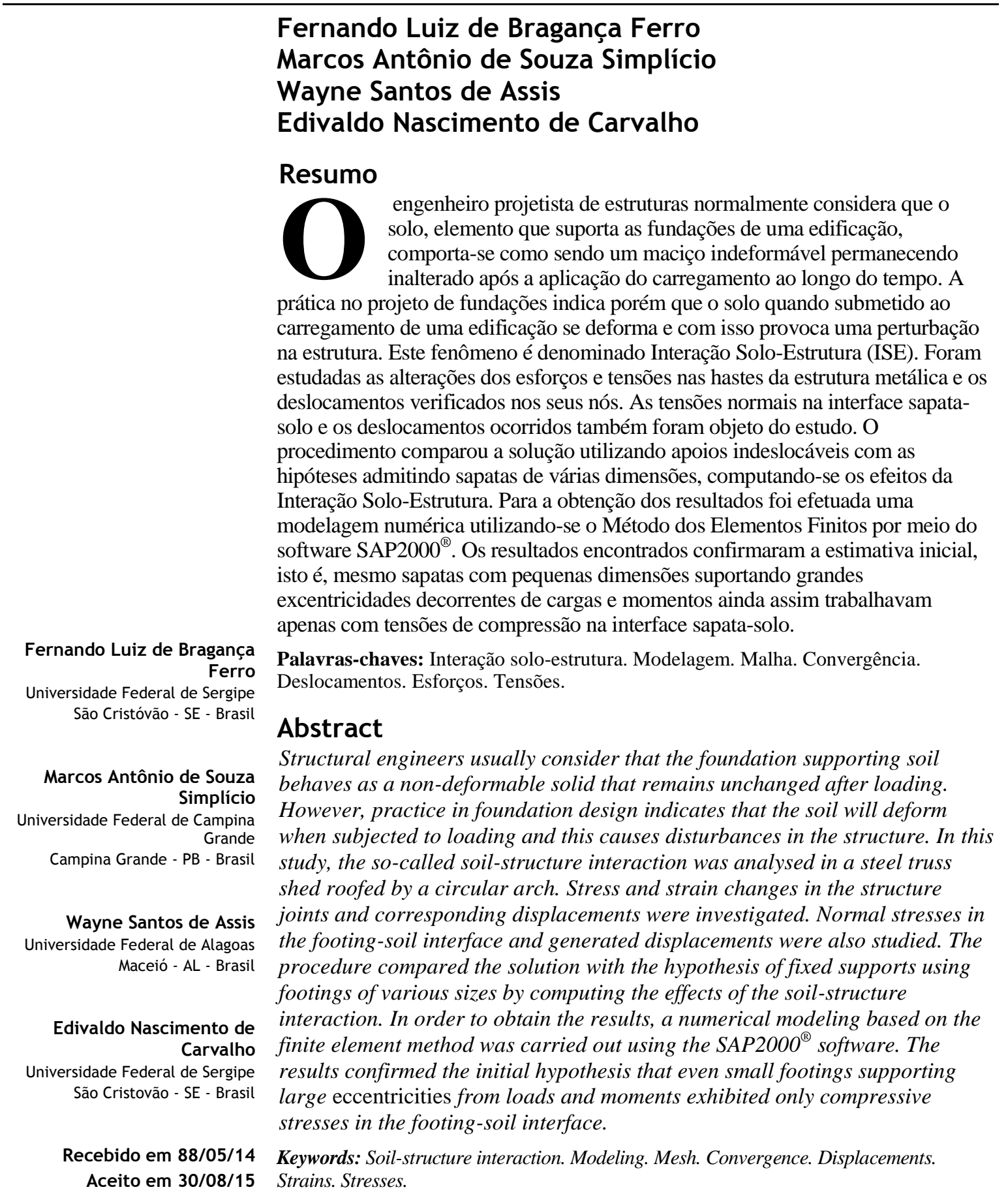




\section{Introdução}

O engenheiro projetista de estruturas normalmente considera que o solo, elemento que suporta as fundações de uma edificação, comporta-se como um maciço indeformável, permanecendo inalterado após a aplicação do carregamento ao longo do tempo. Por conta dessa hipótese, os apoios são projetados para ter comportamento indeslocável, não advindo na estrutura esforços adicionais decorrentes dos deslocamentos não previstos desses suportes.

A partir das magnitudes das cargas e características geológicas e geotécnicas dos solos são determinadas as cotas de assentamento e áreas dos elementos-suporte que irão trabalhar de forma isolada no caso de fundações diretas ou determinam-se a seção transversal e o comprimento do elemento que trabalha por atrito lateral e por ponta, no caso das estacas e tubulões (COLARES, 2006). À medida que a estrutura, ao ser executada, passa a carregar o terreno de fundação que a suporta, tem-se o início do fenômeno denominado interação solo-estrutura. Nesse mecanismo, a edificação que carrega o solo através de suas estruturas de contato, sejam estas fundações diretas, estacas ou tubulões, passa a ter a magnitude de seus esforços alterados em função da mudança de estado das tensões preexistentes no terreno de fundação, decorrentes da construção da edificação (GUSMÃ̃o, 1990). Esse processo de influência mútua entre a superestrutura e a fundação tem seu início ainda na fase construtiva, continuando até que o estado de equilíbrio seja atingido, quando as tensões e deformações se estabilizam, seja na estrutura, seja no maciço de solos (COLARES, 2006).

\section{Revisão bibliográfica}

\section{Modelo de equilíbrio de elementos}

A interação solo-estrutura tem sido estudada nos últimos 30 anos por meio de análise e monitoramento de estruturas (ARSLAN, 2005). Apesar de sua importância, poucos estudos experimentais, seja com modelos de dimensões reais ou em escala reduzida, podem ser encontrados na literatura técnica (TURAN; HINCHBERGER; NAGGAR, 2013). Aoki e Cintra (2004) definem alguns modelos para a análise da interação solo-estrutura que adotam como origem do sistema de referência um ponto localizado sobre a superfície indeslocável. Entre os modelos de equilíbrio de elementos adotados por Aoki e Cintra (2004) foi escolhido como referencial neste trabalho o modelo de um único corpo em equilíbrio formando um sistema global com o contorno, sendo o maciço de solos admitido como indeslocável, conforme Figura 1.

\section{Meio contínuo/Método dos elementos finitos}

Porto (2010) enfatiza que, para a questão da análise da interação solo-estrutura, o método dos elementos finitos poderá ser utilizado tanto para a modelagem da estrutura como para a modelagem do solo da fundação que a suporta, necessitando-se um computador de grande capacidade devido à grande quantidade de graus de liberdade que o problema irá exigir. O método dos elementos finitos permite a modelagem de condições com alto grau de complexidade através de aproximações com grande refinamento, tais como comportamento tensão-deformação não linear, condições não homogêneas de material, mudanças de geometria, entre tantas outras. Porto (2010) sugere cuidado na interpretação dos dados, tendo em vista a possibilidade da ocorrência de imprecisão nos resultados por conta das limitações numéricas.

Figura 1 - Modelo de equilíbrio, estrutura e maciço de solo

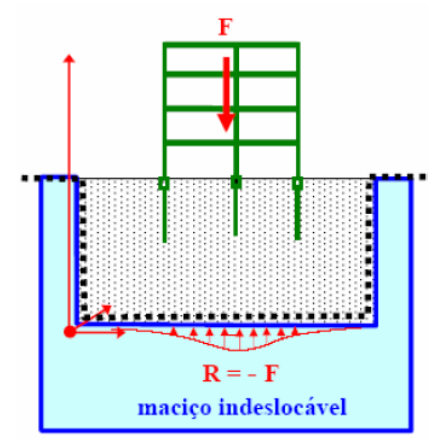

204 Ferro, F. L. de B.; Simplício, M. A. de S.; Assis, W. S. de; Carvalho, E. N. de. 


\section{Modelo teórico}

Nos projetos das fundações de estruturas metálicas as sapatas são, via de regra, projetadas com pequenas dimensões quando comparadas ao vão da estrutura. As cargas normais geralmente são de pequeno valor ante o momento desenvolvido pela diferença nos esforços transmitidos pelos montantes verticais da estrutura metálica. Essa situação provoca grande excentricidade, tornandose imperioso projetar uma sapata com grandes dimensões para anular a possibilidade do efeito de levantamento devido ao surgimento de tensões de tração na interface solo-sapata.

A estrutura objeto do presente estudo é um galpão com pórticos metálicos em arco circular com elementos treliçados em sua seção transversal. O galpão é retangular, com 32,00 m de frente e 60,00 $\mathrm{m}$ de frente a fundo. Os pórticos são em arco circular, com $5,70 \mathrm{~m}$ de cota máxima no centro do vão, vão livre de $30,00 \mathrm{~m}$ entre faces dos pilares extremos, com pé-direito de $8,00 \mathrm{~m}$, e modulação dos pórticos a cada $5,00 \mathrm{~m}$. Optou-se por esse formato para que fosse possível quantificar a influência da interação solo-estrutura nos elementos de barra, seja nos segmentos dos banzos, diagonais do arco ou nos montantes e diagonais dos pilares.

O estudo também avaliou a interação soloestrutura quanto aos valores das tensões normais desenvolvidas na interface sapata-solo em comparação aos valores calculados, admitindo-se o solo como indeformável, e as seções transversais como planas após as deformações.

Os pórticos e vigas longitudinais foram projetados em aço estrutural ASTM A-36, com tensão de escoamento de $250 \mathrm{MPa}$ e tensão de ruptura de $400 \mathrm{MPa}$, com seções transversais conforme o Quadro 1.

As fundações foram projetadas em sapatas isoladas em concreto armado convencional, com $\mathrm{f}_{\mathrm{ck}}$ de 20 $\mathrm{MPa}$, assentes à profundidade de $2 \mathrm{~m}$ em relação ao nível do solo, de formato quadrado, calculadas como sapatas rígidas submetidas à flexotração e flexocompressão em função das cargas transmitidas ao solo pela estrutura metálica.

As ações para o carregamento dos pórticos são mostradas na Tabela 1.

A carga devido à ação do vento foi considerada de acordo com as instruções contidas na norma NBR 6123 (ABNT, 1988), obtendo-se uma pressão dinâmica com o valor de $47 \mathrm{kgf} / \mathrm{m}^{2}$. Utilizou-se o software Autometal ${ }^{\circledR}$ para a obtenção dos coeficientes de pressão e de forma.

Para a determinação das ações e esforços atuantes foram consideradas as normas NBR 8800 (ABNT, 2008) e NBR 8681 (ABNT, 2004). A combinação na qual a ação do vento é tomada como ação variável principal leva aos maiores valores das reações de apoio, parâmetro este de fundamental importância para a avaliação do efeito da interação solo-estrutura.

A Tabela 2 indica os esforços e tensões resistentes obtidos de acordo com a NBR 8800 (ABNT, 2008).

Os valores das reações verticais e das reações horizontais no pilar esquerdo são os maiores encontrados entre as combinações estudadas, estando apresentados na Tabela 3.

\section{Quadro 1 - Formato das seções transversais}

\begin{tabular}{|c|c|}
\hline \multicolumn{2}{|c|}{ PÓRTICOS TRANSVERSAIS } \\
\hline \multicolumn{2}{|c|}{ SEGMENTOS DO ARCO CIRCULAR } \\
\hline Banzos superior e inferior & \multicolumn{1}{c|}{ Perfil U laminado } \\
\hline Diagonais & Cantoneiras L, laminadas, soldadas de topo em U invertido \\
\hline & SEGMENTOS DOS PILARES \\
\hline Montantes & Perfil U laminado \\
\hline Diagonais & Cantoneiras L, laminadas, soldadas de topo em U invertido \\
\hline
\end{tabular}

Tabela 1 - Cargas permanentes e acidentais

\begin{tabular}{|c|c|}
\hline \multicolumn{2}{|c|}{ CARGAS PERMANENTES } \\
\hline Telha ondulada galvanizada (espessura $0,5 \mathrm{~mm}$ ) & $6,00 \mathrm{kgf} / \mathrm{m}^{2}\left(0,06 \mathrm{kN} / \mathrm{m}^{2}\right)$ \\
\hline Contraventamentos & $1,00 \mathrm{kgf} / \mathrm{m}^{2}\left(0,01 \mathrm{kN} / \mathrm{m}^{2}\right)$ \\
\hline Terças & $6,00 \mathrm{kgf} / \mathrm{m}(0,06 \mathrm{kN} / \mathrm{m})$ \\
\hline \multicolumn{2}{|c|}{ CARGAS ACIDENTAIS } \\
\hline Sobrecarga (manutenção do telhado) & $25,00 \mathrm{kgf} / \mathrm{m}^{2}\left(0,25 \mathrm{kN} / \mathrm{m}^{2}\right)$ \\
\hline
\end{tabular}


Tabela 2 - Valores limites - Estrutura metálica (esforços, tensões)

\begin{tabular}{c|c|c}
\hline ELEMENTO & ESFORÇOS \\
ESTRUTURAL & $\begin{array}{c}\text { TENSÕES } \\
\text { RESISTENTES } \\
(+/-)(\mathbf{k N})\end{array}$ & $\begin{array}{c}\text { RESTENTES } \\
(+/)(\mathbf{M P a})\end{array}$ \\
\hline Banzo inferior/Banzo superior do arco & $\mathbf{2 7 7 , 7 0}$ & $\mathbf{6 9 , 7 7}$ \\
Diagonal do arco & $\mathbf{8 7 , 4 1}$ & $\mathbf{8 3 , 4 1}$ \\
Diagonal do pilar & $\mathbf{1 0 9 , 8 0}$ & $\mathbf{1 0 4 , 7 7}$ \\
Montante do pilar & $\mathbf{3 1 8 , 4 0}$ & $\mathbf{8 0 , 0 0}$ \\
\hline
\end{tabular}

Tabela 3 - Reações de apoio - pilar esquerdo

\begin{tabular}{c|c|c}
\hline REAÇÃO DESPERTADA & $\begin{array}{c}\text { MONTANTE } \\
\text { ESQUERDO } \\
(\mathbf{k N})\end{array}$ & $\begin{array}{c}\text { MONTANTE } \\
\text { DIREITO } \\
(\mathbf{k N})\end{array}$ \\
\hline Reação vertical & $\mathbf{+ 1 8 6 , 2 1}$ & $\mathbf{- 1 1 3 , 8 2}$ \\
Reação horizontal & $\mathbf{+ 3 5 , 4 2}$ & $\mathbf{+ 0 , 1 6}$ \\
\hline
\end{tabular}

Figura 2 - Diagrama de tensões na sapata

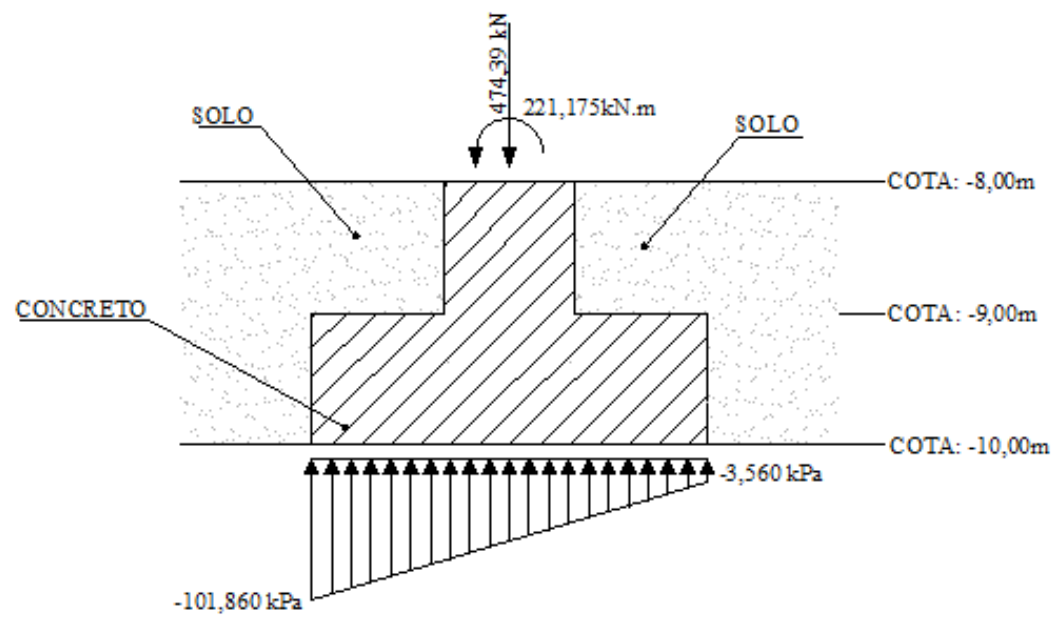

O tipo de sapata escolhido foi sapata rígida, conforme definido pela norma NBR 6118 (ABNT, 2004), em seu item 22.4.1, sendo admitido que a distribuição das tensões normais será linear. Os valores máximos e mínimos das tensões desenvolvidas foram calculados pelas expressões da resistência dos materiais referentes à flexão normal composta com validade apenas para a resultante situada no núcleo central (Equações $1 \mathrm{e}$ 2).

$\sigma_{\text {máx }}=-\mathrm{P} / \mathrm{A}+\mathrm{M}_{\mathrm{y}} \cdot \mathrm{x} / \mathrm{I}_{\mathrm{y}}$

Eq. 1

$\sigma_{\text {mín }}=-\mathrm{P} / \mathrm{A}-\mathrm{M}_{\mathrm{y}} \cdot \mathrm{x} / \mathrm{I}_{\mathrm{y}}$

Eq. 2

A solução encontrada para garantir que na interface sapata-solo só ocorram tensões de compressão foi a de assentar a sapata a uma profundidade de $2,00 \mathrm{~m}$ incorporando o peso próprio do conjunto sapata-pilar. Foi também admitido que o solo acima da sapata trabalhe devidamente compactado quando do reaterro da cava, para que possa, por conta de seu peso próprio, diminuir a excentricidade inicial verificada. As tensões normais verificadas, todas de compressão, para sapata quadrada com $\mathrm{L}=3,00$ $\mathrm{m}$, com altura de $1,00 \mathrm{~m}$ e pescoço da sapata com dimensões de $1,00 \mathrm{~m}$ x 1,00 m x 1,00 m, estão indicadas na Figura 2.

Resta verificar qual a tensão admissível que o solo, para a profundidade de assentamento do conjunto sapata-pilar, poderá suportar. Para esse cálculo ser efetuado é necessário que esteja disponível um perfil de sondagem conhecido, com resultados disponíveis, para servir como parâmetro para o presente estudo. Para tanto foram utilizados dados constantes do trabalho desenvolvido por Souza (2007) referentes aos resultados obtidos do furo SPT 01, executado no Campo Experimental do DEC, Campus da Universidade Federal de Sergipe, no Município de São Cristóvão, no período de 23/11/2005 a 24/11/2005. Esse perfil de sondagem encontra-se indicado na Figura 3. 
Figura 3 - Resultados de sondagem - Furo SPT 01

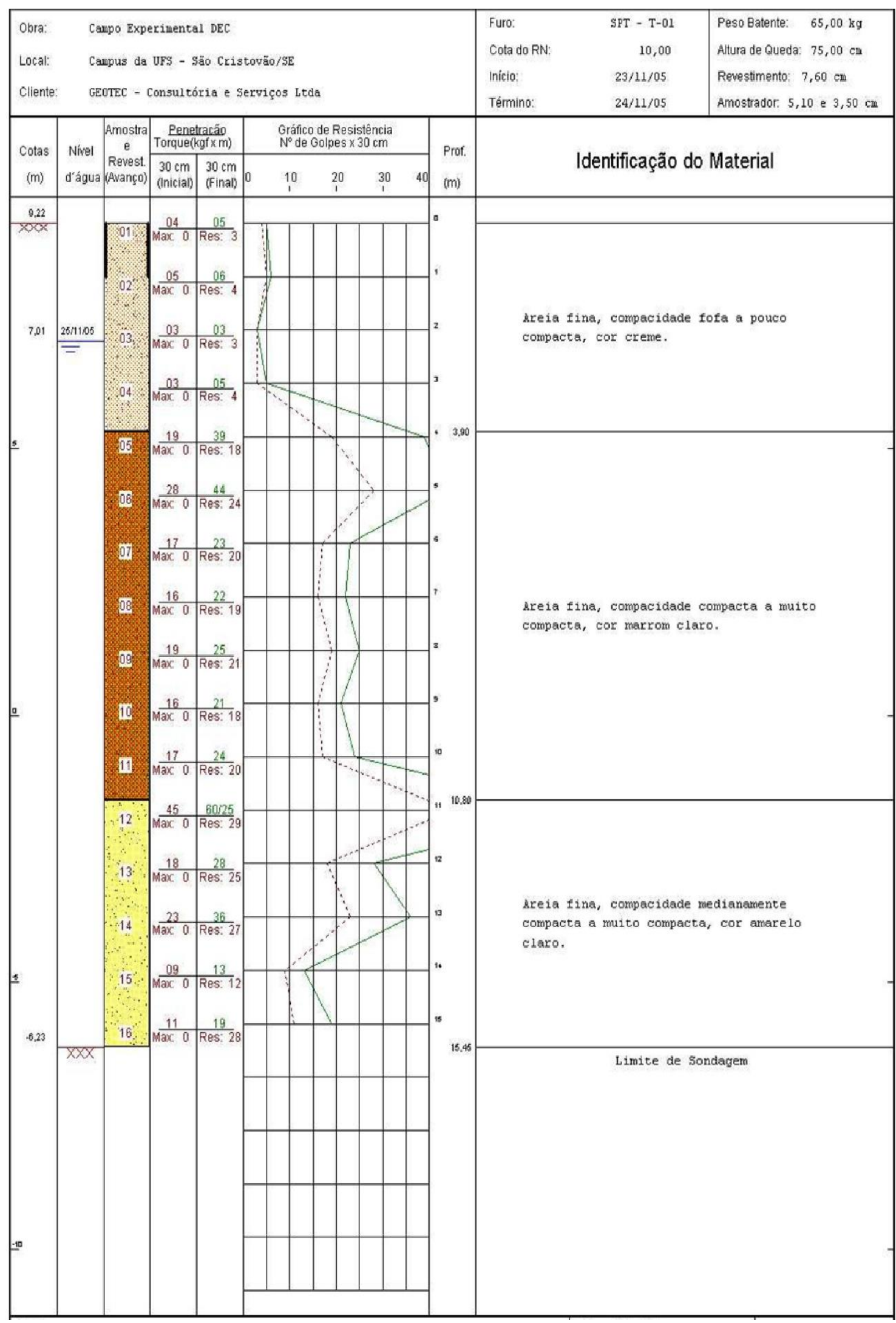


Como foi definida a profundidade em que se optou por assentar a sapata, torna-se necessário estimar qual a tensão admissível que o solo irá suportar. $\mathrm{O}$ procedimento empírico utilizado foi aquele desenvolvido por Bowles (1982), em que são correlacionados vários parâmetros de natureza dimensional da sapata e geotécnica $\left(\mathrm{N}_{\mathrm{SPT}}\right.$ e profundidade de assentamento) do solo, conforme as expressões dadas pelas Equações 3 e 4 :

$\mathrm{K}_{\mathrm{d}}=1+\left(0,33 \times \mathrm{D}_{\mathrm{f}}\right) / \mathrm{B}$ com $\mathrm{K}_{\mathrm{d}} \leq 1,33 \quad$ Eq. 3
$\sigma_{\mathrm{adm}}=\left(\mathrm{N}_{\text {MÉDIO }} / \mathrm{B}\right)+[(\mathrm{B}+0,3) / \mathrm{B}] \times \mathrm{K}_{\mathrm{d}}$ em kgf $/$
$\mathrm{cm}^{2}$

Onde:

$D_{\mathrm{f}}$ é a cota de assentamento da sapata em metros;

B é a largura da sapata em metros;

$\mathrm{K}_{\mathrm{d}}$ é o coeficiente de ajuste;

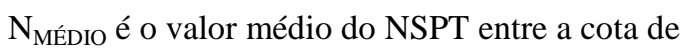
assentamento da sapata e a profundidade de 2B abaixo dessa cota; e

$\sigma_{\text {adm }}$ é a tensão admissível no solo suporte.

Com as dimensões da sapata, sua cota de assentamento e resultados da sondagem do solo já obtidos anteriormente, passou-se a determinar os parâmetros de entrada conforme as expressões 3 e 4, obtendo-se:

$\mathrm{D}_{\mathrm{f}}=2,00 \mathrm{~m}$;

$\mathrm{B}=3,00 \mathrm{~m}$;

$\mathrm{K}_{\mathrm{d}}=1,22 ; \mathrm{e}$

$\mathrm{N}_{\text {MÉDIO }}=14$

A tensão admissível encontrada para o solo suporte, utilizando-se o procedimento empírico desenvolvido por Bowles (1982), é 2,3485 $\mathrm{kgf} / \mathrm{cm}^{2}$.

O valor encontrado em MPa é de 0,23485 e em $\mathrm{kPa}, \sigma_{\mathrm{adm}}=235 \mathrm{kPa}$.

Com base na tensão admissível encontrada, verifica-se que o valor máximo das tensões normais compostas indicadas na Figura 2, de 102 $\mathrm{kPa}$, é inferior ao que o solo pode suportar.

\section{Modelagem numérica}

Para efetuar o estudo do real comportamento do solo quando carregado por uma estrutura e os reflexos que serão gerados no próprio maciço e na estrutura que o carrega, o que caracteriza o fenômeno solo-estrutura, foi utilizado o software SAP $2000^{\circledR}$. Este programa utiliza o método de elementos finitos CSI (COMPUTERS..., 2005), com interface gráfica em $3 \mathrm{D}$, em que foram escolhidos os elementos que caracterizam os diferentes componentes estruturais que irão interagir, sendo o elemento Frame ${ }^{\circledR}$ para a estrutura metálica e o elemento Asolid ${ }^{\circledR}$ para os pilares, sapatas e maciço de solo no entorno. A partir daí, procedeu-se à modelagem do solo, sapatas, pilares e barras da estrutura metálica.

A origem do sistema de coordenadas ortogonais está localizada na extremidade superior, no montante direito do pilar esquerdo na junção da diagonal com o arco treliçado, conforme indicado na Figura 4, que apresenta no plano $\mathrm{XY}$ as dimensões do maciço, em planta baixa, com a definição dos limites conforme as características da estrutura piloto. Como forma de avaliar a influência da interação solo-estrutura, variaram-se as dimensões das sapatas e passou-se a analisar o efeito dessa redução no resultado das tensões e deslocamentos da estrutura. Para tal, foram modeladas sapatas quadradas com lados iguais a 3 $\mathrm{m}$, a $2 \mathrm{~m}$ e a $1,5 \mathrm{~m}$.

A Figura 5 apresenta em corte XZ a estrutura metálica com a indicação dos horizontes de solo utilizados no presente estudo.

A malha inicial tem as dimensões do elemento unitário representativo do estado triaxial de

tensões com valores de $1,00 \mathrm{~m} \times 1,00 \mathrm{~m} \times 1,00 \mathrm{~m} \mathrm{e}$ $0,50 \mathrm{~m} \times 1,00 \mathrm{~m} \times 1,00 \mathrm{~m}$, conforme representação em 3D para o carregamento mais desfavorável indicado na Figura 6.

$\mathrm{Na}$ análise inicial verificou-se que a parte central do maciço, com $20 \mathrm{~m}$ na direção longitudinal e 10 $\mathrm{m}$ na direção transversal, não tem influência nos resultados. No perímetro dessa região os deslocamentos e tensões normais na direção vertical têm valores próximos de zero. As dimensões do maciço, visando ao refinamento dos resultados, terão $11 \mathrm{~m}$ na direção transversal e 10 m na direção longitudinal, com as dimensões dos sólidos apresentados na Figura 7.

Após o refinamento da malha chega-se aos números apresentados na Tabela 4.

\section{Análise dos resultados}

A interação solo-estrutura provoca deslocamentos nas sapatas de fundação do pórtico intermediário, alterando com isso a posição final dos nós da estrutura metálica. A identificação de algumas barras utilizadas na análise é apresentada na Figura 8. 
Figura 4 - Dimensões-limite do maciço do solo / Plano XY / Cota Z = -8

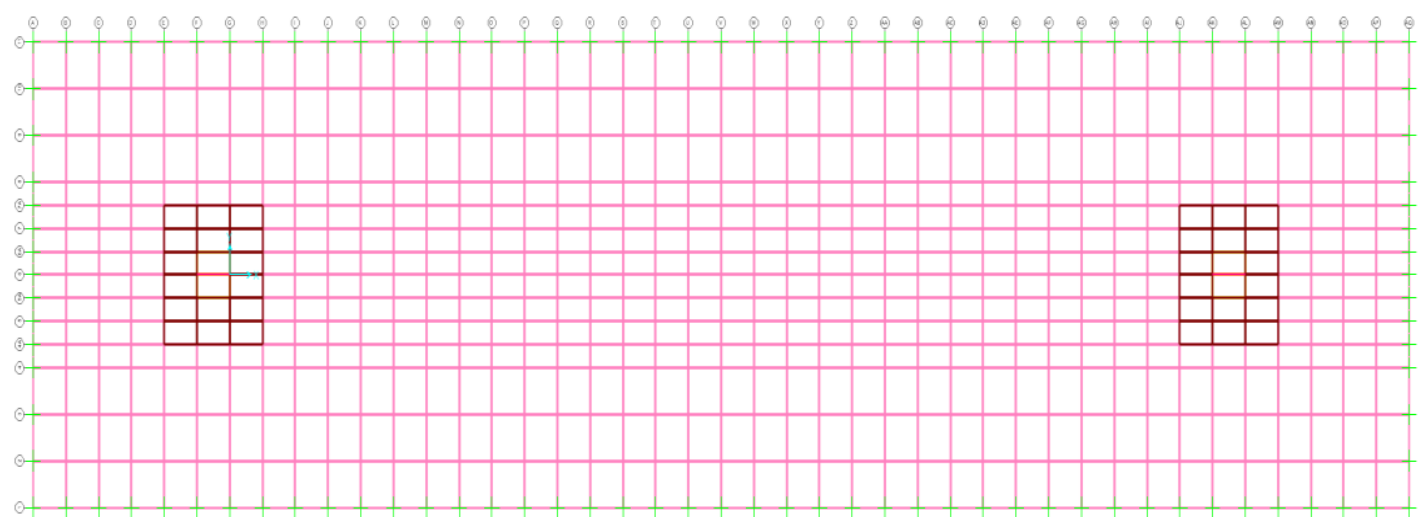

Figura 5 - Dimensões-limite do maciço do solo / Plano XZ

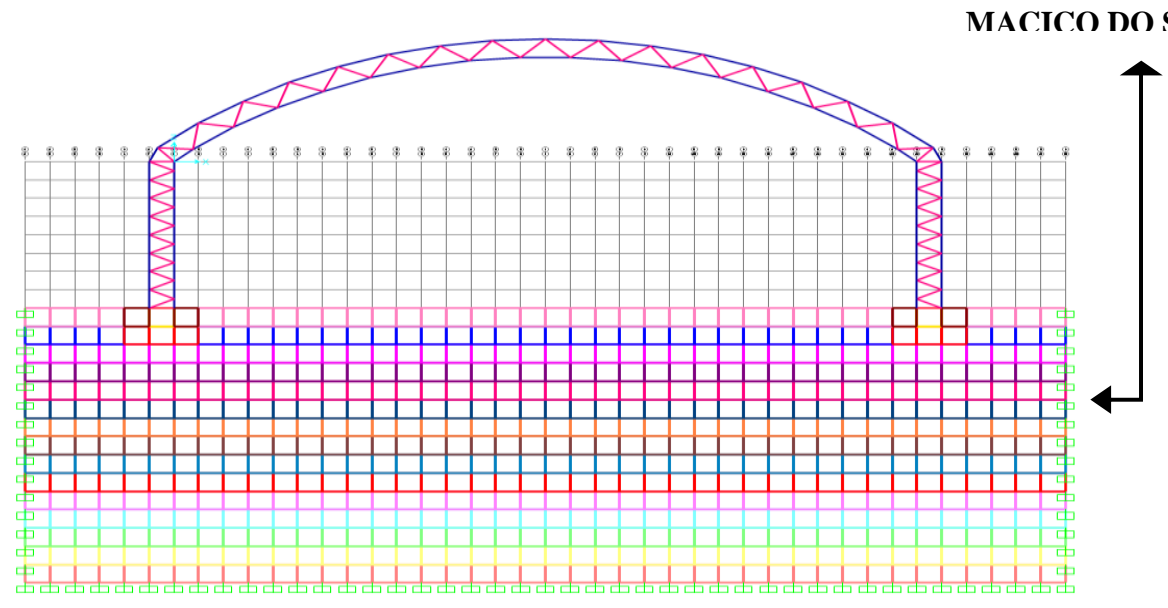

Figura 6 - Estrutura carregada + Pilares + Sapatas + Solo / Vista 3D

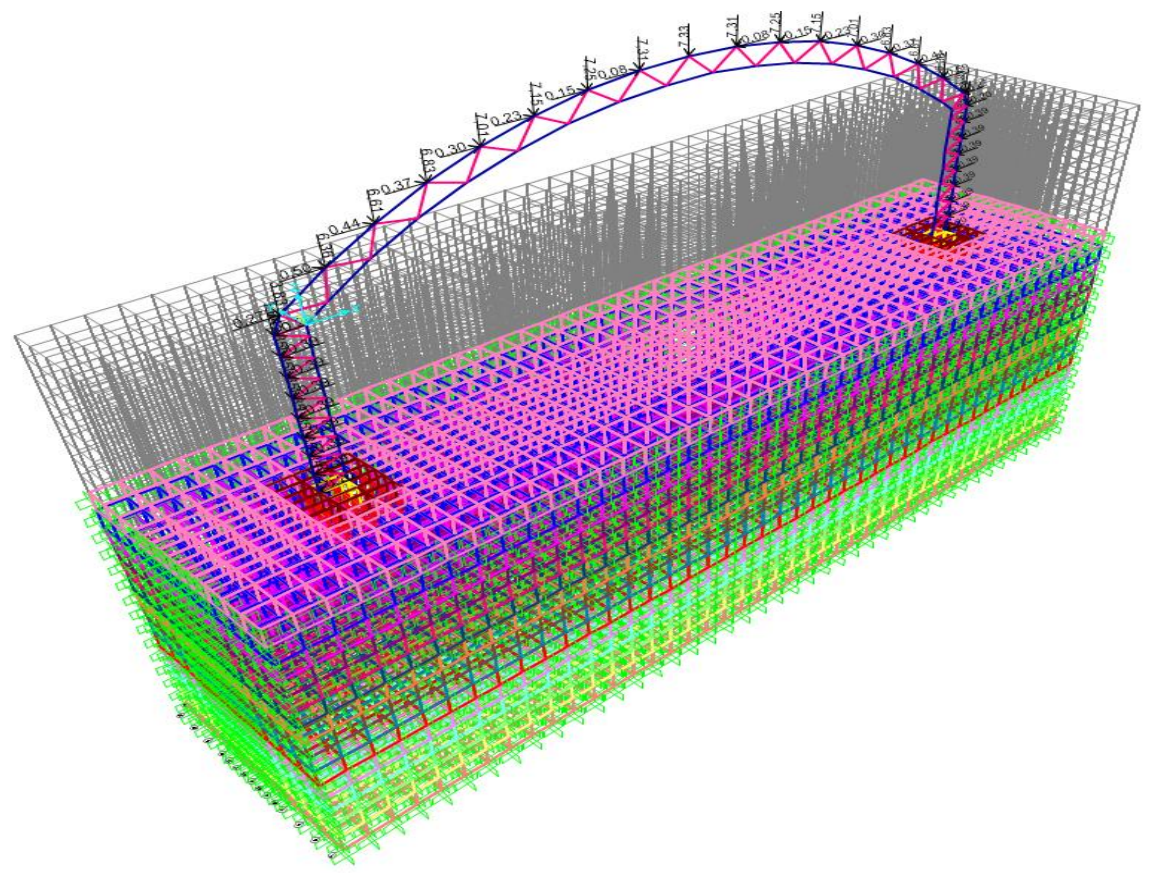


Figura 7 - Sólidos: $(0,25$ x 0,25 x 0,25) m - Nível: $-8 \mathrm{~m}$ a -14 m - Sólidos: $(0,25$ x 0,25 x 0,50) m - Nível: $-14 \mathrm{~m}$ a $-23 \mathrm{~m}$

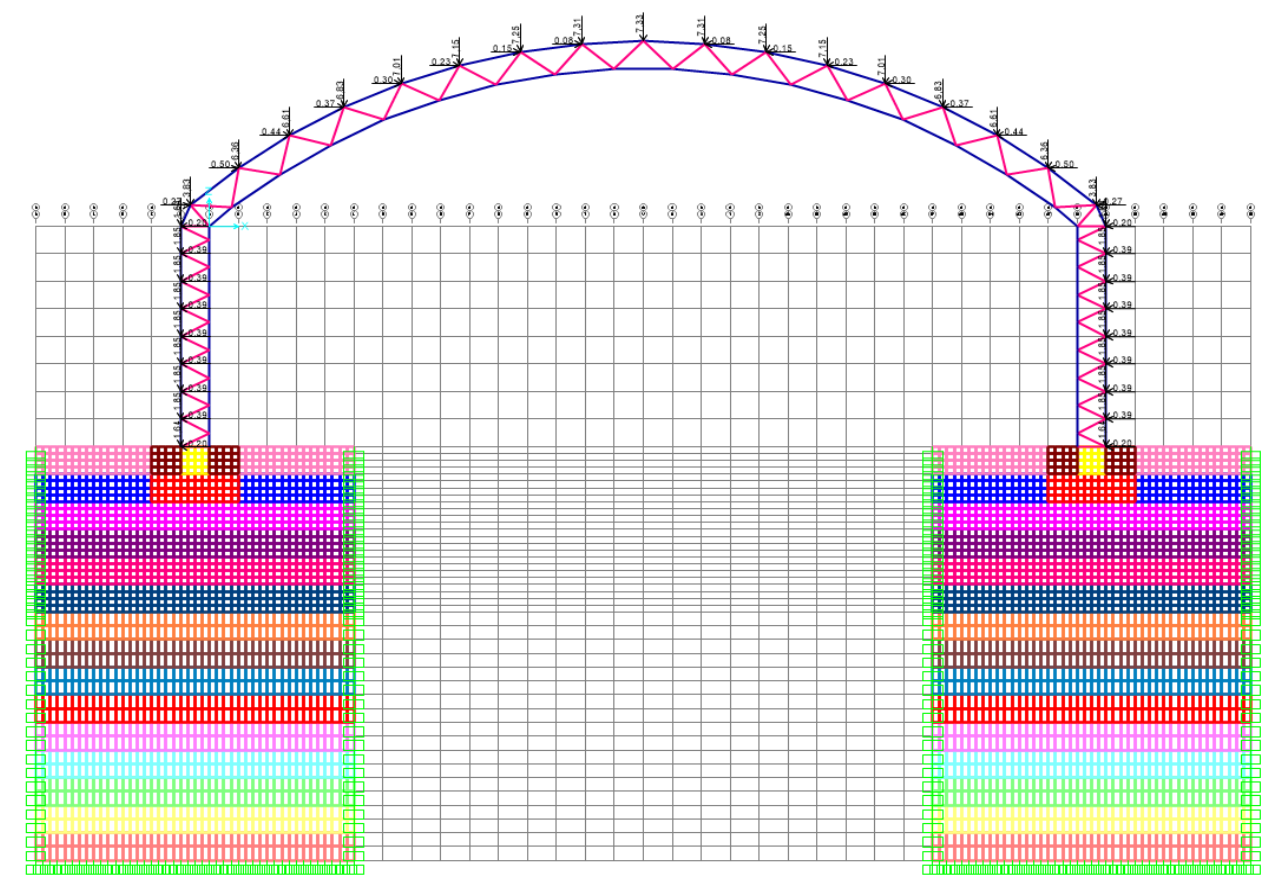

Tabela 4 - Número de elementos e nós utilizados

\begin{tabular}{c|c}
\hline Item & Quantidade \\
\hline Número de nós processados & 158.737 \\
Número de restrições no contorno & 17.805 \\
Número de elementos de barras & 145 \\
Número de elementos sólidos & 147.840 \\
\hline
\end{tabular}

Figura 8 - Estrutura metálica (identificação das barras)

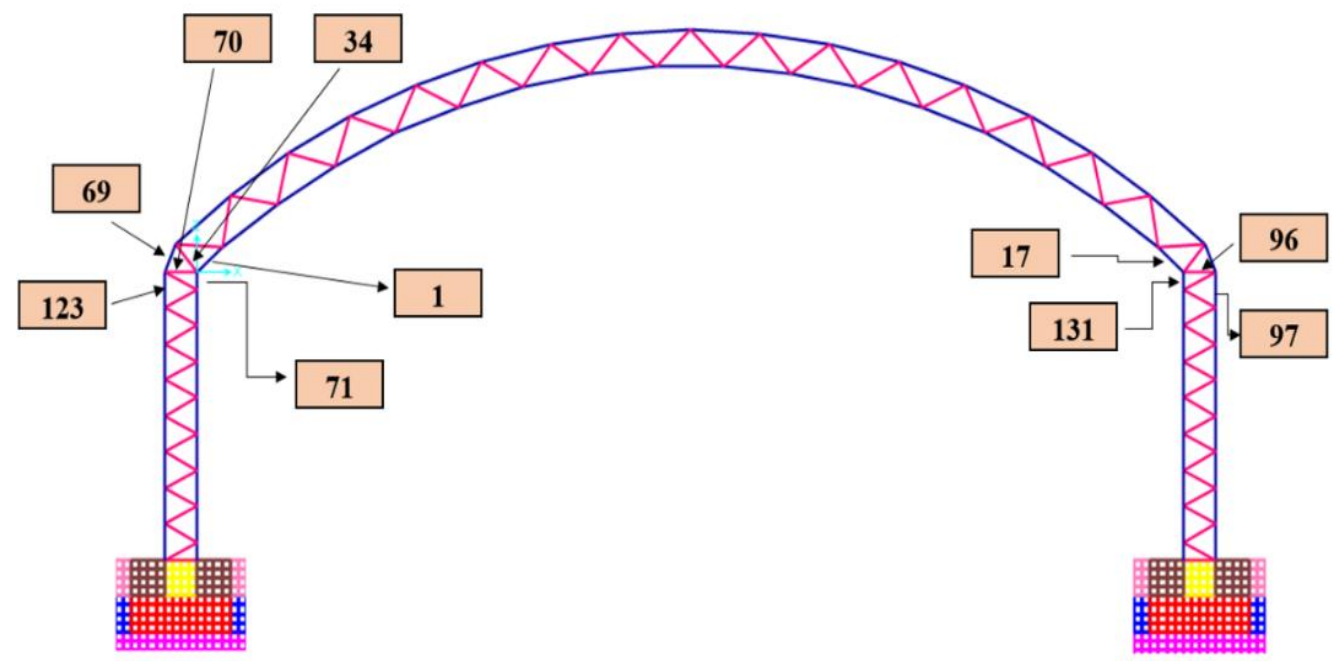

210 Ferro, F. L. de B.; Simplício, M. A. de S.; Assis, W. S. de; Carvalho, E. N. de. 
A Tabela 5 mostra uma visão geral dos deslocamentos e rotações para as duas hipóteses admitidas, com e sem a admissão da ocorrência da interação solo-estrutura, considerando sapatas de 3 $\mathrm{m} \times 3 \mathrm{~m}$. Nota-se o aumento nos deslocamentos e rotações dos nós em análise. Também é possível verificar que os deslocamentos verticais aumentaram de forma mais acentuada.

A estrutura metálica encontra-se indicada na Figura 9, com a identificação de alguns nós que foram objeto da análise.
A Tabela 6 indica os esforços e tensões obtidos sendo consideradas as duas hipóteses: apoio fixo e o solo como elemento deformável. É possível notar que algumas barras tiveram decréscimo de tensão, enquanto em outras ocorreu aumento de valores.

A Figura 10 apresenta o bulbo de tensões na sapata esquerda para o carregamento indicado.

Tabela 5 - Deslocamentos lineares e angulares nos modelos indeslocável e deslocável - sapata $3 \mathrm{~m} \times 3$ m com interação solo-estrutura

\begin{tabular}{|c|c|c|c|c|c|c|}
\hline \multirow[b]{2}{*}{ Nó } & \multicolumn{3}{|c|}{ Sistema Indeslocável } & \multicolumn{3}{|c|}{$\begin{array}{c}\text { Sistema Deslocável } \\
\text { (Interação solo-estrutura) }\end{array}$} \\
\hline & $\begin{array}{l}\text { Desloc. } \\
\text { Horiz. } \\
\text { (mm) }\end{array}$ & $\begin{array}{c}\text { Desloc. } \\
\text { Vert. } \\
\text { (mm) }\end{array}$ & $\begin{array}{c}\text { Desloc. } \\
\text { Ang. } \\
\left({ }^{\circ}\right)\end{array}$ & $\begin{array}{l}\text { Desloc. } \\
\text { Horiz. } \\
\text { (mm) }\end{array}$ & $\begin{array}{c}\text { Desloc. } \\
\text { Vert. } \\
(\mathbf{m m})\end{array}$ & $\begin{array}{c}\text { Desloc. } \\
\text { Ang. } \\
\left({ }^{\circ}\right)\end{array}$ \\
\hline 3962 & $-5,60$ & $-0,39$ & $-0,011$ & $-6,47$ & $-3,26$ & $-0,003$ \\
\hline 3883 & $-5,77$ & $-0,27$ & $-0,015$ & $-6,61$ & $-3,25$ & $-0,002$ \\
\hline 3936 & 5,77 & $-0,27$ & 0,015 & 6,61 & $-3,25$ & 0,002 \\
\hline 3978 & 5,60 & $-0,39$ & 0,011 & 6,47 & $-3,26$ & 0,003 \\
\hline 3908 & $-0,08$ & $-14,68$ & 0,013 & $-0,09$ & $-19,28$ & 0,014 \\
\hline
\end{tabular}

Figura 9 - Estrutura metálica (identificação dos nós)

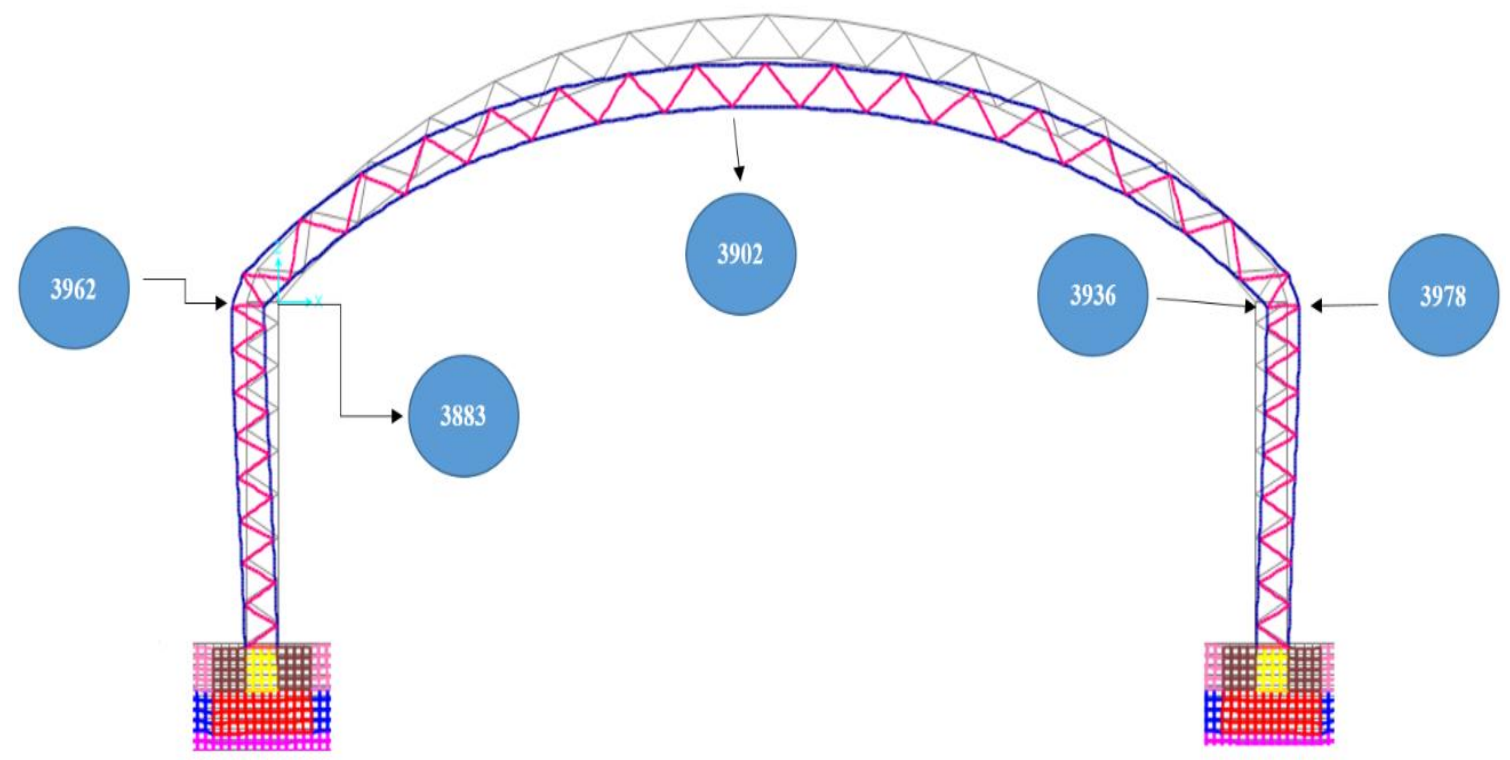


Tabela 6 - Estrutura metálica / Quadro comparativo / Esforços / Tensões - Sistema indeslocável x Sistema deslocável (Sapata $3 \mathrm{~m}$ x 3 m com Interação solo-estrutura)

\begin{tabular}{|c|c|c|c|c|c|c|c|c|}
\hline \multirow[b]{2}{*}{ BARRA } & \multicolumn{2}{|c|}{ Sistema Indeslocável } & \multicolumn{2}{|c|}{$\begin{array}{c}\text { Sistema Deslocável } \\
\text { (Interação solo-estrutura) }\end{array}$} & \multicolumn{4}{|c|}{ Análise Comparativa } \\
\hline & $\begin{array}{c}\text { Esforço } \\
\text { Verificado } \\
(\mathbf{k N})\end{array}$ & $\begin{array}{c}\text { Tensão } \\
\text { Verificada } \\
\text { (MPa) }\end{array}$ & $\begin{array}{c}\text { Esforço } \\
\text { Verificado } \\
(\mathbf{k N})\end{array}$ & $\begin{array}{c}\text { Tensão } \\
\text { Verificada } \\
\text { (MPa) }\end{array}$ & \multicolumn{2}{|c|}{$\begin{array}{l}\text { Esforço } \\
\text { Resistente } \\
(\mathbf{k N})\end{array}$} & \multicolumn{2}{|c|}{$\begin{array}{c}\text { Tensão } \\
\text { Resistente } \\
\text { (MPa) }\end{array}$} \\
\hline$\overline{1}$ & $-163,04$ & $-40,96$ & $-166,37$ & $-41,80$ & 277,70 & ok & 69,77 & ok \\
\hline 17 & $-158,52$ & $-39,83$ & $-160,11$ & $-40,23$ & 277,70 & ok & 69,77 & ok \\
\hline 69 & 111,12 & 27,92 & 117,08 & 29,42 & 277,70 & ok & 69,77 & ok \\
\hline 34 & $-69,12$ & $-65,95$ & $-68,08$ & $-64,96$ & 87,41 & ok & 83,41 & ok \\
\hline 96 & $-73,87$ & $-70,49$ & $-59,33$ & $-56,61$ & 109,80 & ok & 104,77 & ok \\
\hline 97 & 80,17 & 20,14 & 91,86 & 23,08 & 318,40 & ok & 80,00 & ok \\
\hline 131 & $-152,82$ & $-38,40$ & $-156,41$ & $-39,30$ & 318,40 & ok & 80,00 & ok \\
\hline 70 & $-75,77$ & $-72,30$ & $-61,54$ & $-58,72$ & 109,80 & ok & 104,77 & ok \\
\hline 71 & $-157,45$ & $-39,56$ & $-162,79$ & $-40,90$ & 318,40 & ok & 80,00 & ok \\
\hline 123 & 84,32 & 21,19 & 97,83 & 24,58 & 318,40 & ok & 80,00 & ok \\
\hline
\end{tabular}

Figura 10 - Bulbo de tensões normais verticais $S_{33}$ / Sapata esquerda $(L=3,00 \mathrm{~m})$

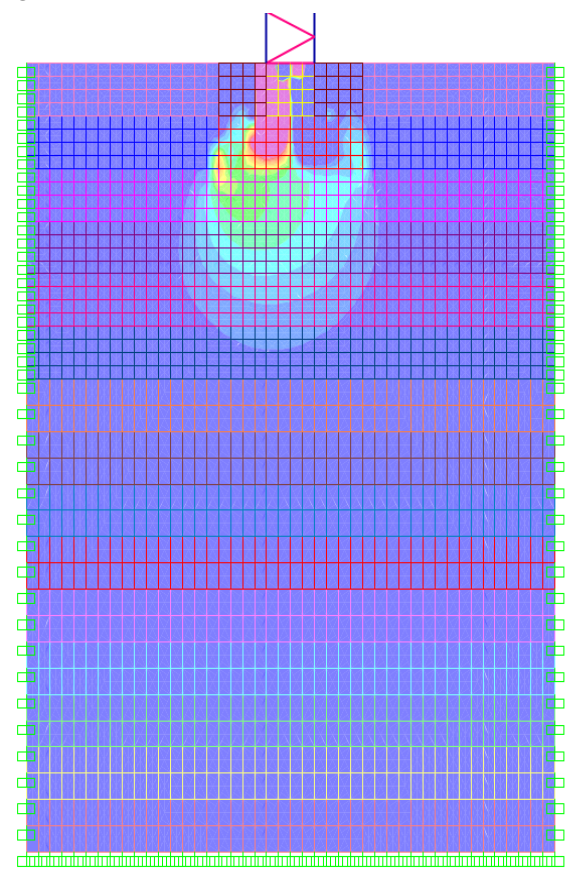

A Tabela 7 apresenta os indicadores para a sapata esquerda, bem como permite comparar os resultados, admitindo flexão composta, com aqueles obtidos através da interação solo-estrutura.

Os valores das tensões obtidas estão indicados na Figura 11, admitindo-se a hipótese de flexão composta na interface sapata-solo na cota de $10,00 \mathrm{~m}$ e o resultado da análise considerando a interação solo-estrutura.

Nota-se que a distribuição de tensões não é linear, como sugere o modelo teórico de sapata rígida, ocorrendo, além disso, diminuição dessas tensões.
A Tabela 8 apresenta os deslocamentos dos nós da estrutura metálica apoiada em sapata com dimensões $2 \mathrm{~m}$ x $2 \mathrm{~m}$. Neste caso também há acréscimo de deslocamentos quando se considera a interação solo-estrutura.

A Tabela 9 indica os esforços e tensões normais que se desenvolvem na estrutura metálica considerando-se a interação solo-estrutura com sapatas de $2 \mathrm{~m}$ x $2 \mathrm{~m}$. Também apresenta uma comparação com o sistema inicialmente admitido como indeslocável. Apesar do acréscimo de tensão em alguns elementos, estas tensões continuam com valores abaixo das tensões resistentes de cálculo. 
Tabela 7 - Indicadores / Sapata esquerda ( $L$ = 3,00 m) / Cota: -10,00 m / Flexão composta x Interação

\begin{tabular}{|c|c|c|c|c|c|}
\hline \multirow[b]{3}{*}{ Nó } & \multirow[b]{3}{*}{ COORDENADAS } & \multirow[b]{3}{*}{\begin{tabular}{|c|} 
TENSẼ NORMAL \\
CALCCULO \\
ADMITINDO \\
SAPATA RIGIDA \\
[FLEXAO COMPOSTA) \\
$\mathbf{S}_{33}$ \\
(kPa)
\end{tabular}} & \multirow{2}{*}{\multicolumn{3}{|c|}{$\begin{array}{l}\text { TRELICCA METÁLICA COM INTERACÃO SOLO-ESTRUTURA } \\
\text { COTA: -10 (FUNDO DA SAPATA) }\end{array}$}} \\
\hline & & & & & \\
\hline & & & \begin{tabular}{|c|} 
TENSAO NORMAL \\
CALLCULO ADMITINDO \\
INTERACAOO SOLO-ESTRUTURA \\
\\
[SAPATA $3 \mathrm{~m} \times \mathbf{3} \mathrm{m}$ ] \\
$\mathbf{S}_{33}$ \\
$(\mathbf{k P a})$
\end{tabular} & \begin{tabular}{|c|} 
DESLOCAMENTO \\
LINEAR \\
[SAPATA $3 \mathrm{~m} \times 3 \mathrm{~m}]$ \\
Eixo $\mathrm{Z}$ \\
\\
$\mathbf{U}_{3}$ \\
{$[\mathrm{~mm}]$}
\end{tabular} & $\begin{array}{c}\text { VARIACAO } \\
\text { TENSAO NORMAL } \\
\text { INTERACAOAO SOLO-ESTRUTURA } \\
\times \\
\text { SAPATA RiGiDA } \\
\text { S }_{33} \\
(\%)\end{array}$ \\
\hline 9052 & $(X=-2,00 ; Y=0,00)$ & -102 & -52 & -4 & -48 \\
\hline 125374 & $(X=-1,75 ; Y=0,00)$ & -94 & -27 & -4 & -71 \\
\hline 125382 & $(X=-1,50 ; Y=0,00)$ & -85 & -32 & -4 & -62 \\
\hline 125390 & $(X=-1,25 ; Y=0,00)$ & -77 & -35 & -4 & -55 \\
\hline 9067 & $(X=-1,00 ; Y=0,00)$ & -69 & -37 & -3 & -46 \\
\hline 125607 & $(X=-0,75 ; Y=0,00)$ & -61 & -34 & -3 & -44 \\
\hline 125615 & $(X=-0,50 ; Y=0,00)$ & -53 & -27 & -3 & -49 \\
\hline 125623 & $(X=-0,25 ; Y=0,00)$ & -45 & -19 & -3 & -58 \\
\hline 9082 & $(X=0,00 ; Y=0,00)$ & -36 & -16 & -3 & -57 \\
\hline 125840 & $(X=0,25 ; Y=0,00)$ & -28 & -16 & -3 & -42 \\
\hline 125848 & $(X=0,50 ; Y=0,00)$ & -20 & -18 & -3 & -8 \\
\hline 125856 & $(X=0,75 ; Y=0,00)$ & -12 & -18 & -2 & 50 \\
\hline 9097 & $(X=1,00 ; Y=0,00)$ & -4 & -26 & -2 & 638 \\
\hline
\end{tabular}

Figura 11 - Tensões $S_{33}$ / Sapata esquerda $(L=3,00 \mathrm{~m})$ / Cota: $-10,00 \mathrm{~m} /$ Interface sapata-solo

$\rightarrow$ TENSÃo NORMAL CÁLCULO ADMITINDO SAPATA RÍGIDA (FLEXÃo COMPOSTA) S33(kPa)

-- TENSÃO NORMAL CÁLCULO ADMITINDO INTERAC̣̃̃ SOLO-ESTRUTURA (SAPATA $3 \mathrm{~m} \times 3$ m) S33 (kPa)

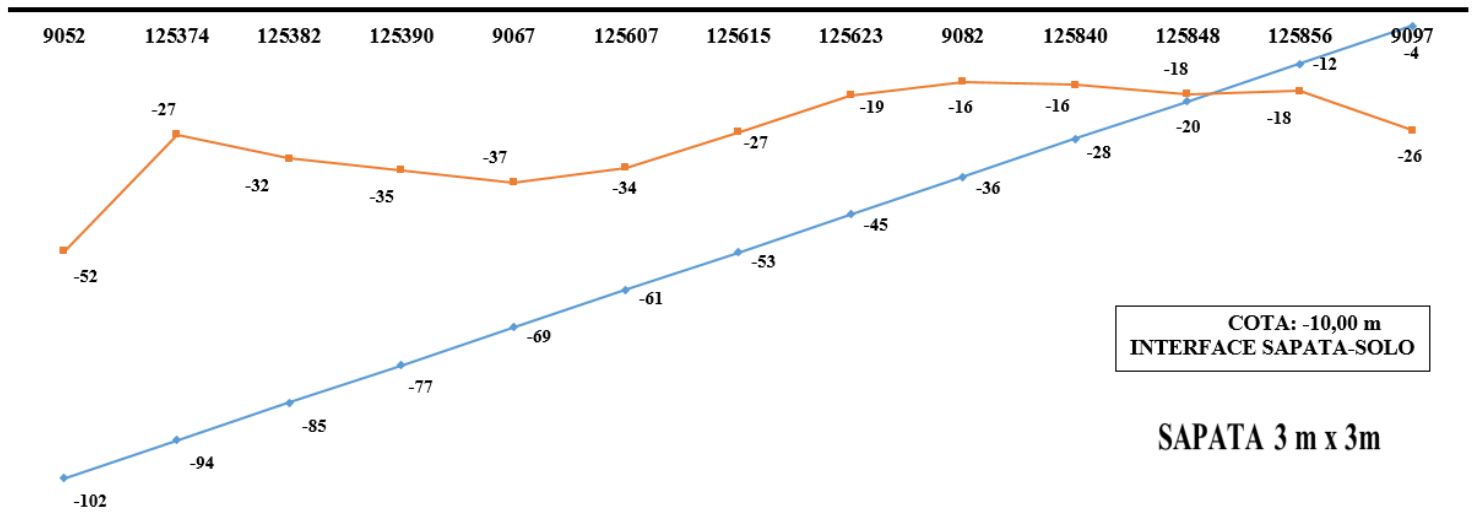

Tabela 8 - Deslocamentos lineares e angulares nos modelos indeslocável e deslocável - Sapata 2 m x 2 m com Interação solo-estrutura

\begin{tabular}{c|c|c|c|c|c|c}
\hline \multirow{3}{*}{ Nó } & \multicolumn{3}{|c|}{ Sistema Indeslocável } & \multicolumn{2}{c}{ Sistema Deslocável (Interação solo-estrutura) } \\
\cline { 2 - 7 } & $\begin{array}{c}\text { Desloc. } \\
\text { Horiz. } \\
(\mathbf{m m})\end{array}$ & $\begin{array}{c}\text { Desloc. } \\
\text { Vert. } \\
(\mathbf{m m})\end{array}$ & $\begin{array}{c}\text { Desloc. } \\
\text { Ang. } \\
\left({ }^{\circ}\right)\end{array}$ & $\begin{array}{c}\text { Desloc. } \\
\text { Horiz. } \\
(\mathbf{m m})\end{array}$ & $\begin{array}{c}\text { Desloc. } \\
\text { Vert. } \\
(\mathbf{m m})\end{array}$ & $\begin{array}{c}\text { Desloc. } \\
\text { Ang. } \\
\left({ }^{\circ}\right)\end{array}$ \\
\hline 3962 & $-5,60$ & $-0,39$ & $-0,011$ & $-7,11$ & $-2,82$ & 0,001 \\
3883 & $-5,77$ & $-0,27$ & $-0,015$ & $-7,25$ & $-2,88$ & 0,003 \\
3936 & 5,77 & $-0,27$ & 0,015 & 7,25 & $-2,88$ & $-0,003$ \\
3978 & 5,60 & $-0,39$ & 0,011 & 7,11 & $-2,82$ & $-0,001$ \\
3908 & $-0,08$ & $-14,68$ & 0,013 & $-0,10$ & $-20,15$ & 0,015 \\
\hline
\end{tabular}


Tabela 9 - Esforços e tensões nos modelos indeslocável e deslocável - Sapata 2 m x 2 m com Interação solo-estrutura

\begin{tabular}{|c|c|c|c|c|c|c|c|c|}
\hline \multirow[b]{2}{*}{ BARRA } & \multicolumn{2}{|c|}{ Sistema Indeslocável } & \multicolumn{2}{|c|}{$\begin{array}{c}\text { Sistema Deslocável } \\
\text { (Interação solo-estrutura) }\end{array}$} & \multicolumn{4}{|c|}{ Análise Comparativa } \\
\hline & $\begin{array}{c}\text { Esforço } \\
\text { Verificado } \\
(\mathbf{k N}) \\
\end{array}$ & $\begin{array}{c}\text { Tensão } \\
\text { Verificada } \\
\text { (MPa) }\end{array}$ & $\begin{array}{c}\text { Esforço } \\
\text { Verificado } \\
(\mathbf{k N})\end{array}$ & $\begin{array}{c}\text { Tensão } \\
\text { Verificada } \\
\text { (MPa) }\end{array}$ & \multicolumn{2}{|c|}{$\begin{array}{l}\text { Esforço } \\
\text { Resistente } \\
\text { (kN) }\end{array}$} & \multicolumn{2}{|c|}{$\begin{array}{c}\text { Tensão } \\
\text { Resistente } \\
\text { (MPa) }\end{array}$} \\
\hline 1 & $-163,04$ & $-40,96$ & $-172,00$ & $-43,22$ & 277,70 & $\overline{\text { ok }}$ & 69,77 & $\overline{\text { ok }}$ \\
\hline 17 & $-158,52$ & $-39,83$ & $-164,17$ & $-41,25$ & 277,70 & ok & 69,77 & ok \\
\hline 69 & 111,12 & 27,92 & 124,91 & 31,38 & 277,70 & ok & 69,77 & ok \\
\hline 34 & $-69,12$ & $-65,95$ & $-72,58$ & $-69,26$ & 87,41 & ok & 83,41 & ok \\
\hline 96 & $-73,87$ & $-70,49$ & $-59,77$ & $-57,03$ & 109,80 & ok & 104,77 & ok \\
\hline 97 & 80,17 & 20,14 & 98,60 & 24,77 & 318,40 & ok & 80,00 & ok \\
\hline 131 & $-152,82$ & $-38,40$ & $-162,05$ & $-40,72$ & 318,40 & ok & 80,00 & ok \\
\hline 70 & $-75,77$ & $-72,30$ & $-62,55$ & $-59,69$ & 109,80 & ok & 104,77 & ok \\
\hline 71 & $-157,45$ & $-39,56$ & $-170,03$ & $-42,72$ & 318,40 & ok & 80,00 & ok \\
\hline 123 & 84,32 & 21,19 & 106,12 & 26,66 & 318,40 & ok & 80,00 & ok \\
\hline
\end{tabular}

Tabela 10 - Indicadores / Sapata esquerda $(L=2,00$ m) / Cota: -10,00 m / Flexão composta x Interação

\begin{tabular}{|c|c|c|c|c|c|}
\hline \multirow[b]{4}{*}{ Nó } & \multirow[b]{4}{*}{ COORDENADAS } & \multirow[b]{4}{*}{\begin{tabular}{|c|} 
TENSĀO NORMAL \\
CALCULO \\
ADMITINDO \\
SAPATA RÍGIDA \\
(FLEXAOO COMPOSTA) \\
$\mathbf{S}_{\mathbf{3 3}}$ \\
(kPa)
\end{tabular}} & \multicolumn{3}{|c|}{ TRELICCA METÁLICA COM INTERAČ̃̃O SOLO-ESTRUTURA } \\
\hline & & & \multicolumn{3}{|c|}{ COTA: -10 [ FUNDO DA SAPATA ] } \\
\hline & & & \multicolumn{3}{|c|}{ SAPATA $2 \mathrm{~m} \times 2 \mathrm{~m}$} \\
\hline & & & \begin{tabular}{|c|} 
TENSAO NORMMAL \\
CALCULO ADMITINDO \\
INTERACAO SOLO-ESTRUTURA \\
[SAPATA $2 \mathrm{~m} \times 2 \mathrm{~m}$ ] \\
\\
$\mathbf{S}_{33}$ \\
$(\mathrm{kPa})$
\end{tabular} & \begin{tabular}{|c|} 
DESLOCAMENTO \\
LINEAR \\
Eixo $\mathrm{Z}$ \\
[SAPATA $2 \mathrm{~m} \times 2 \mathrm{~m}]$ \\
$\mathrm{U}_{3}$ \\
{$[\mathrm{~mm}]$}
\end{tabular} & $\begin{array}{c}\text { VARIACCAO } \\
\text { TENSAO NORMAL } \\
\text { INTERAÇAO SOLO-ESTRUTURA } \\
\times \\
\text { SAPATA RÍGIDA } \\
\text { S }_{33} \\
{[\%]}\end{array}$ \\
\hline 115226 & $(X=-1,50 ; Y=0,00)$ & -230 & -58 & -4 & -75 \\
\hline 115267 & $(X=-1,25 ; Y=0,00)$ & -188 & -30 & -4 & -84 \\
\hline 115308 & $(X=-1,00 ; Y=0,00)$ & -147 & -37 & -3 & -75 \\
\hline 115349 & $(X=-0,75 ; Y=0,00)$ & -105 & -32 & -3 & -69 \\
\hline 115390 & $(X=-0,50 ; Y=0,00)$ & -64 & -27 & -3 & -58 \\
\hline 115431 & $(X=-0,25 ; Y=0,00)$ & -22 & -19 & -3 & -16 \\
\hline 115472 & $(X=0,00 ; Y=0,00)$ & 20 & -14 & -2 & -171 \\
\hline 115513 & $(X=0,25 ; Y=0,00)$ & 61 & -13 & -2 & -121 \\
\hline 115554 & $(X=0,50 ; Y=0,00)$ & 103 & -17 & -2 & -116 \\
\hline
\end{tabular}

A Tabela 10, por sua vez, indica os deslocamentos na cota $-10,00 \mathrm{~m}$, contato da sapata com o solo, tensões normais na direção vertical e deslocamentos. Ao se incluir na análise a interação solo-estrutura, é possível ver a diminuição das tensões normais.

Em alguns casos houve inversão de sinal, com nós submetidos a tensões de tração passando a estar sob tensões de compressão.

A Figura 12 apresenta o bulbo de tensões normais $\mathrm{S}_{33}$ para a sapata esquerda $(\mathrm{L}=2,00 \mathrm{~m})$, admitindo-se o efeito da interação solo-estrutura.

As tensões normais no eixo $\mathrm{Y}$ para a sapata esquerda na interface com o solo estão indicadas na Figura 13 de forma comparativa com a hipótese inicial, ou seja, sistema indeslocável. Nota-se uma uniformização das tensões normais obtidas com a análise numérica. Em termos práticos, a ação predominante é a carga normal.

O quadro com os deslocamentos dos nós da estrutura metálica adotando sapata com dimensões $\mathrm{L}=1,50 \mathrm{~m}$, admitindo-se a interação soloestrutura, está apresentado na Tabela $11 \mathrm{em}$ comparação com o sistema indeslocável inicialmente admitido no estudo. Da mesma forma que para as sapatas com dimensões maiores ( $3 \mathrm{~m} \mathrm{e}$ $2 \mathrm{~m}$ ), também há aumento dos deslocamentos, principalmente na vertical.

A Tabela 12 indica a comparação dos resultados ante a alternativa inicial de indeformabilidade dos apoios-suporte da treliça em estudo. Nota-se que as 
tensões atuantes continuam inferiores às tensões resistentes.

As tensões e os deslocamentos na cota $-10,00 \mathrm{~m}$, interface sapata-solo, admitindo-se os efeitos da interação solo-estrutura para a sapata com $\mathrm{L}=1,50$ m, são apresentados na Tabela 13 para aqueles nós de interesse locados no eixo baricêntrico Y.

Figura 12 - Bulbo de tensões normais verticais $S_{33}$. / Sapata esquerda $(L=2,00 \mathrm{~m})$

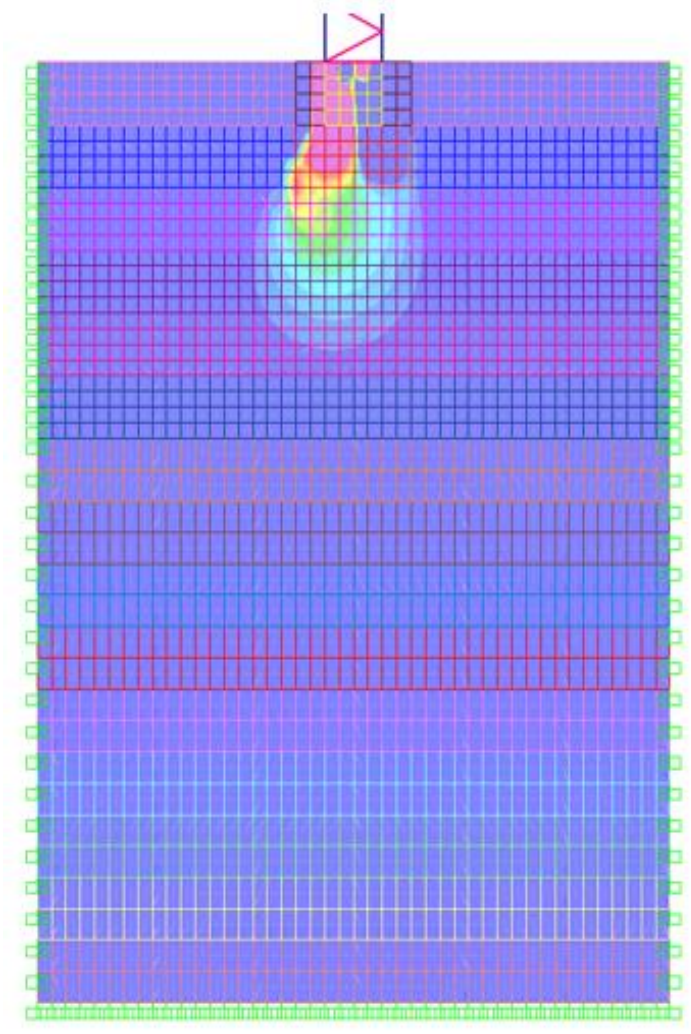

Figura 13 - Tensões $S_{33} /$ Sapata esquerda $(L=2,00 \mathrm{~m})$ / Cota: $-10,00 \mathrm{~m} /$ Interface sapata-solo - Flexão composta $\mathrm{x}$ Interação solo-estrutura

— TENSÃO NORMAL CÁLCULO ADMITINDO SAPATA RÍGIDA (FLEXÃO COMPOSTA) S33 (kPa)

—TENSÃO NORMAL CÁLCULO ADMITINDO INTERAÇÃO SOLO-ESTRUTURA (SAPATA $2 \mathrm{~m} \times 2 \mathrm{~m}$ ) $\$ 33$ (kPa)

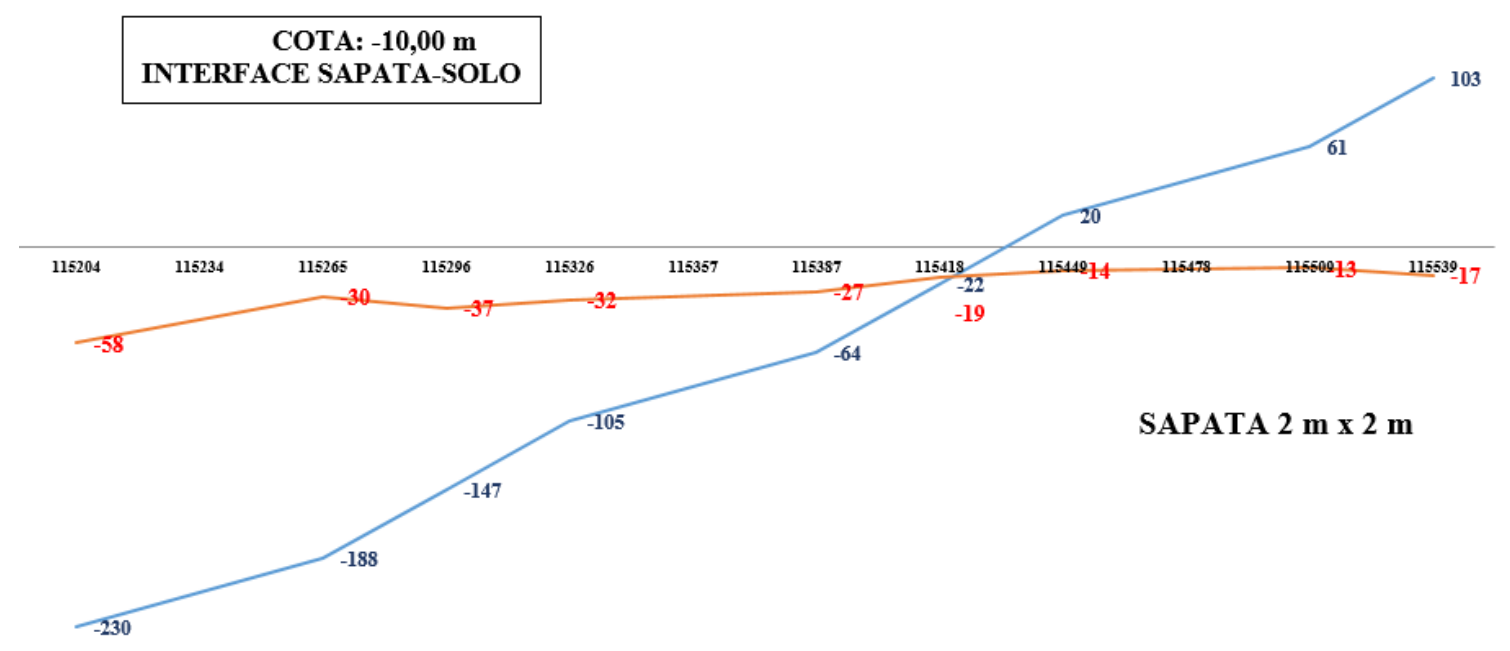


Tabela 11 - Deslocamentos lineares e angulares nos modelos indeslocável e deslocável - Sapata 1,5 m x 1,5 m com interação solo-estrutura

\begin{tabular}{|c|c|c|c|c|c|c|}
\hline \multirow[b]{2}{*}{ Nó } & \multicolumn{3}{|c|}{ Sistema Indeslocável } & \multicolumn{3}{|c|}{$\begin{array}{c}\text { Sistema Deslocável (Interação solo- } \\
\text { estrutura) }\end{array}$} \\
\hline & $\begin{array}{c}\text { Desloc. } \\
\text { Horiz. } \\
(\mathrm{mm})\end{array}$ & $\begin{array}{c}\text { Desloc. } \\
\text { Vert. } \\
(\mathrm{mm})\end{array}$ & $\begin{array}{c}\text { Desloc. } \\
\text { Ang. } \\
\left({ }^{\circ}\right)\end{array}$ & $\begin{array}{c}\text { Desloc. } \\
\text { Horiz. } \\
(\mathrm{mm}) \\
\end{array}$ & $\begin{array}{c}\text { Desloc. } \\
\text { Vert. } \\
\text { (mm) }\end{array}$ & $\begin{array}{c}\text { Desloc. } \\
\text { Ang. } \\
\left({ }^{\circ}\right)\end{array}$ \\
\hline 3962 & $-5,60$ & $-0,39$ & $-0,011$ & $-7,48$ & $-2,60$ & 0,003 \\
\hline 3883 & $-5,77$ & $-0,27$ & $-0,015$ & $-7,63$ & $-2,69$ & 0,006 \\
\hline 3936 & 5,77 & $-0,27$ & 0,015 & 7,63 & $-2,69$ & $-0,006$ \\
\hline 3978 & 5,60 & $-0,39$ & 0,011 & 7,48 & $-2,60$ & $-0,003$ \\
\hline 3908 & $-0,08$ & $-14,68$ & 0,013 & $-0,11$ & $-20,68$ & 0,015 \\
\hline
\end{tabular}

Tabela 12 - Esforços e tensões nos modelos indeslocável e deslocável - Sapata 1,5 m x 1,5 m com interação solo-estrutura

\begin{tabular}{|c|c|c|c|c|c|c|c|c|}
\hline \multirow[b]{2}{*}{ BARRA } & \multicolumn{2}{|c|}{ Sistema Indeslocável } & \multicolumn{2}{|c|}{$\begin{array}{c}\text { Sistema Deslocável } \\
\text { (Interação solo-estrutura) }\end{array}$} & \multicolumn{4}{|c|}{ Análise Comparativa } \\
\hline & $\begin{array}{c}\text { Esforço } \\
\text { Verificado } \\
(\mathbf{k N})\end{array}$ & $\begin{array}{c}\text { Tensão } \\
\text { Verificada } \\
\text { (MPa) }\end{array}$ & $\begin{array}{c}\text { Esforço } \\
\text { Verificado } \\
(\mathbf{k N})\end{array}$ & $\begin{array}{c}\text { Tensão } \\
\text { Verificada } \\
\text { (MPa) }\end{array}$ & $\begin{array}{r}\text { Esfor } \\
\text { Resist } \\
(k N\end{array}$ & & $\begin{array}{r}\text { Tens } \\
\text { Resist } \\
\text { (MP }\end{array}$ & \\
\hline 1 & $-163,04$ & $-40,96$ & $-175,59$ & $-44,07$ & 277,70 & $\overline{\text { ok }}$ & 69,77 & $\overline{\text { ok }}$ \\
\hline 17 & $-158,52$ & $-39,83$ & $-166,54$ & $-41,84$ & 277,70 & ok & 69,77 & ok \\
\hline 69 & 111,12 & 27,92 & 129,82 & 32,62 & 277,70 & ok & 69,77 & ok \\
\hline 34 & $-69,12$ & $-65,95$ & $-75,37$ & $-71,92$ & 87,41 & ok & 83,41 & ok \\
\hline 96 & $-73,87$ & $-70,49$ & $-60,02$ & $-57,27$ & 109,80 & ok & 104,77 & ok \\
\hline 97 & 80,17 & 20,14 & 102,58 & 25,77 & 318,40 & ok & 80,00 & ok \\
\hline 131 & $-152,82$ & $-38,40$ & $-165,37$ & $-41,55$ & 318,40 & ok & 80,00 & ok \\
\hline 70 & $-75,77$ & $-72,30$ & $-63,23$ & $-60,33$ & 109,80 & ok & 104,77 & ok \\
\hline 71 & $-157,45$ & $-39,56$ & $-174,59$ & $-43,87$ & 318,40 & ok & 80,00 & ok \\
\hline 123 & 84,32 & 21,19 & 111,31 & 27,97 & 318,40 & ok & 80,00 & ok \\
\hline
\end{tabular}

Tabela 13 - Indicadores / Sapata esquerda $(L=1,50 \mathrm{~m})$ / Cota: -10,00 m / Flexão composta x Interação

\begin{tabular}{|c|c|c|c|c|c|}
\hline \multirow[b]{3}{*}{ Nó } & \multirow[b]{3}{*}{ COORDENADAS } & \multirow[b]{3}{*}{ 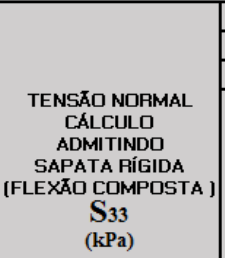 } & \multirow{2}{*}{\multicolumn{3}{|c|}{$\begin{array}{l}\text { TRELIĊA METÁLICA COM INTERAÇÃO SOLO-ESTRUTURA } \\
\text { COTA: -10 (FUNDO DA SAPATA) } \\
\end{array}$}} \\
\hline & & & \multicolumn{2}{|c|}{ SAPATA $1,5 \mathrm{~m} \times 1,5 \mathrm{~m}$} & \\
\hline & & & \begin{tabular}{|c|}
$\begin{array}{c}\text { TENSKO NORMAL } \\
\text { CALCULO ADMITINDO } \\
\text { INTERACAO SOLO-ESTRUTURA } \\
\\
\mathbf{S}_{33} \\
(\mathrm{kPa})\end{array}$
\end{tabular} & \begin{tabular}{|c|} 
DESLOCAMENTO \\
LINEAR \\
Eixo Z \\
$\mathbf{U}_{3}$ \\
[mm]
\end{tabular} & \begin{tabular}{|c|} 
VARIACAOA \\
TENSAO NORMAL \\
INTERACAO SOLO-ESTRUTURA \\
$\times$ \\
SAPATA RIGIDA \\
S $_{33}$ \\
$(\%)$
\end{tabular} \\
\hline 115267 & $(\mathrm{X}=-1,25 ; \mathrm{Y}=0,00)$ & -472 & -61 & -4 & -87 \\
\hline 115308 & $(X=-1,00 ; Y=0,00)$ & -341 & -32 & -4 & -91 \\
\hline 115349 & $(X=-0,75 ; Y=0,00)$ & -210 & -31 & -3 & -85 \\
\hline 115390 & $(\mathrm{X}=-0,50 ; \mathrm{Y}=0,00)$ & -79 & -25 & -3 & -69 \\
\hline 115431 & $(X=-0,25 ; Y=0,00)$ & 52 & -19 & -2 & -136 \\
\hline 115472 & $(X=0,00 ; Y=0,00)$ & 183 & -13 & -2 & -107 \\
\hline 115513 & $(X=0,25 ; Y=0,00)$ & 314 & -14 & -2 & -104 \\
\hline
\end{tabular}

As tensões normais, com a interação solo-estrutura sendo admitida, estão apresentadas na imagem do bulbo de tensões normais para a sapata esquerda, conforme a Figura 14, a seguir. Já a Figura 15 apresenta as tensões normais para a mesma sapata, no contato com o solo, de forma a compará-las com a hipótese de flexão composta apresentada inicialmente. Nota-se que as tensões decorrentes da análise numérica são de compressão e tendem a um valor uniforme. Com a deformabilidade do conjunto sapata-solo sendo computada, tudo se passa como se a sapata estivesse submetida apenas a esforços normais de compressão. 
Figura 14 - Bulbo de tensões normais verticais $S_{33}$. / Sapata esquerda $(L=1,50 \mathrm{~m})$

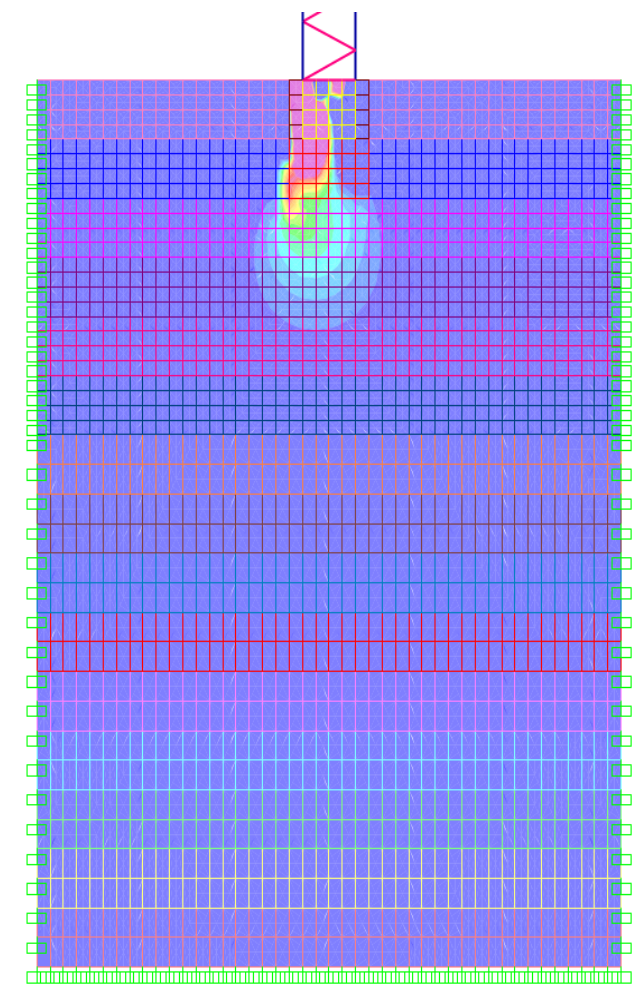

Figura 15 - Tensões $S_{33} /$ Sapata esquerda $(L=1,50 \mathrm{~m}) /$ Cota: $-10,00 \mathrm{~m} /$ Interface sapata-solo

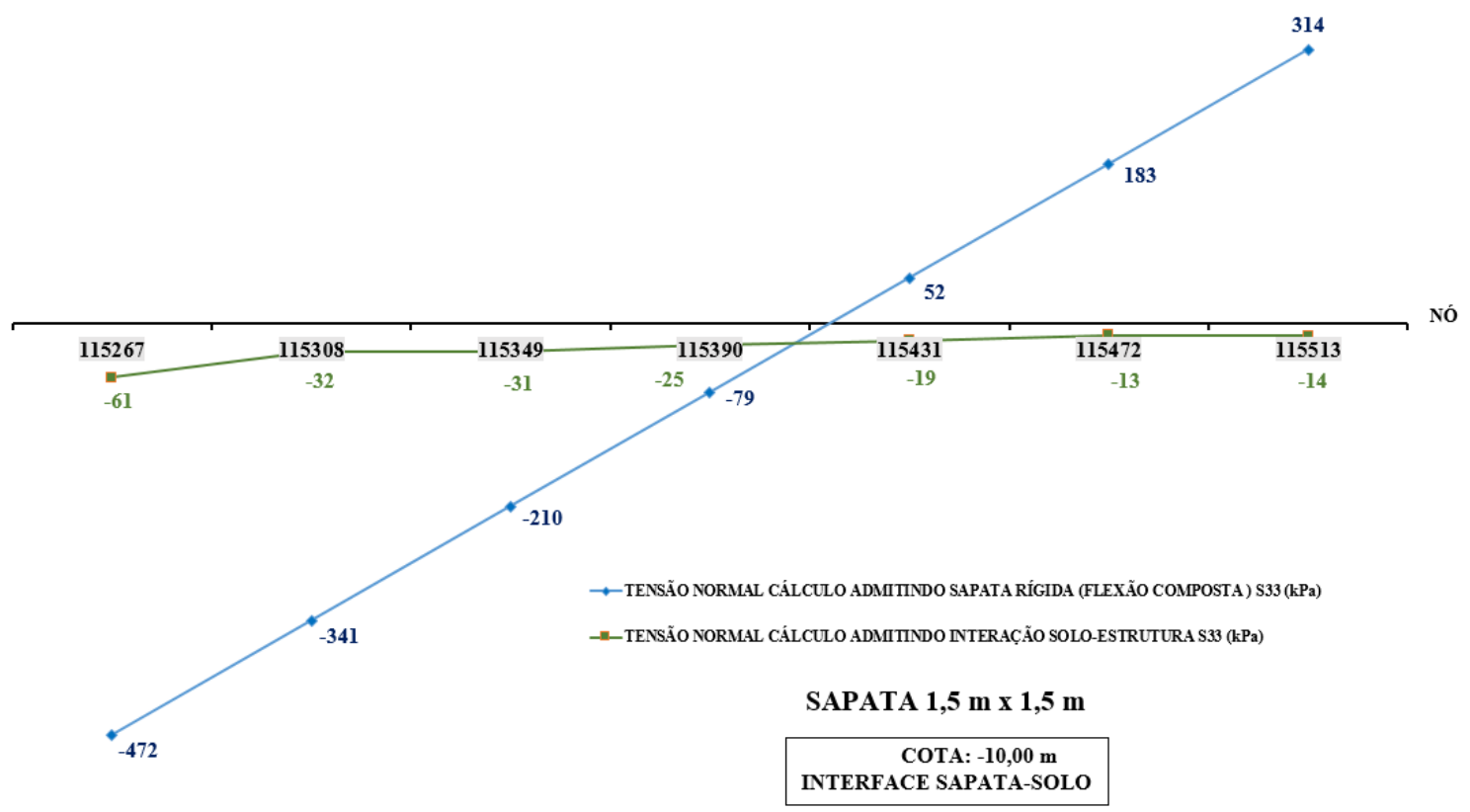

\section{Conclusões}

As estruturas dos tipos pré-moldados e as metálicas, apesar de transferirem ao solo cargas normais e momentos, em algumas situações são projetadas levando-se em consideração apenas as primeiras, resultando então em sapatas de dimensões inadequadas, de acordo com os procedimentos clássicos de dimensionamento. Para investigar essa aparente incoerência, foi escolhido um galpão metálico treliçado em arco circular. Efetuou-se a modelagem numérica considerado a inclusão dos efeitos advindos do fenômeno da interação solo-estrutura. Em seguida foram 
avaliadas as tensões e os deslocamentos nos pontos de contato das sapatas com o solo suporte, os deslocamentos lineares e angulares nos nós da estrutura metálica e os esforços e tensões aí desenvolvidos. Baseando-se nas análises descritas ao longo deste trabalho, pode-se concluir que:

(a) os deslocamentos verificados nos nós da estrutura metálica, bem como os esforços e tensões nas barras aumentam à medida que a interação solo-estrutura do conjunto é computada e passa-se a reduzir as dimensões das sapatas. Entretanto, os deslocamentos e as tensões verificadas nas barras ainda se encontram abaixo dos limites máximos especificados em norma;

(b) os deslocamentos verificados nos pontos de contato da sapata com o solo, quando a interação solo-estrutura tem seus efeitos considerados e as dimensões das sapatas são reduzidas, apresentam variações para mais e para menos conforme os nós se aproximam das ações de carga ou alívio provocadas pelos montantes da estrutura metálica;

(c) por conta dos efeitos da interação soloestrutura, verifica-se que os esforços verticais desenvolvidos nos montantes do pilar esquerdo decrescem quando comparados com os resultados sob a hipótese de apoios indeslocáveis, continuando com essa tendência à medida que as dimensões das sapatas são reduzidas;

(d) a resultante horizontal no topo do pilar esquerdo, quando da consideração dos efeitos da interação solo-estrutura, tem sua intensidade reduzida quando as dimensões das sapatas passam do valor $L=3,00 \mathrm{~m}$ para $\mathrm{L}=1,50 \mathrm{~m}$;

(e) o efeito da interação solo-estrutura provoca a redução do momento que solicita o topo do pilar esquerdo, decrescendo desde a hipótese de apoios indeslocáveis até a menor dimensão calculada da sapata $\mathrm{L}=1,50 \mathrm{~m}$; e

(f) os resultados obtidos levam a crer que, apesar de a estrutura metálica se apoiar nas sapatas por intermédio de 2 montantes verticais em cada uma delas, a estrutura se comporta como se a ligação fosse feita através de um único ponto articulado, e assim só transmite esforços verticais, sem a existência de momentos aplicados no solo.

Todas as conclusões acima relatadas são válidas para o caso em questão, ou seja, arco circular, não atirantado, com pilares metálicos treliçados. Para extrapolação dessas afirmações faz-se necessário um estudo mais aprofundado, com um número maior de variáveis envolvidas.

\section{Referências}

AOKI, N.; CINTRA, J. C. [Notas de Aula da Disciplina SGS-404 Fundações]. Departamento de Geotecnia, Escola de Engenharia, Universidade de São Paulo, São Carlos, 2004.

ARSLAN, H. Finite Element study of Soil Structure Interface Problem. The Electronic Journal of Geotechnical Engineering, v. 10, 2005.

\section{ASSOCIAÇÃO BRASILEIRA DE NORMAS}

TÉCNICAS. NBR 6118: projeto de estruturas de concreto. Rio de Janeiro, 2004.

\section{ASSOCIAÇÃO BRASILEIRA DE NORMAS}

TÉCNICAS. NBR 6123: forças devidas ao vento em edificações. Rio de Janeiro, 1988.

\section{ASSOCIAÇÃO BRASILEIRA DE NORMAS}

TÉCNICAS. NBR 8800: projeto de estruturas de aço e de estruturas mistas de aço e concreto. Rio de Janeiro, 2008.

BOWLES, J. E. Foundation Analysis and Design. Singapore: McGraw-Hill Book Co., 1982.

COLARES, G. M. Programa Para Análise da Interação Solo-Estrutura no Projeto de Edifícios. São Carlos, 2006. Dissertação (Mestrado em Engenharia Civil) - Escola de Engenharia de São Carlos, Universidade de São Paulo, São Carlos, 2006.

COMPUTERS AND STRUCTURES INC. Analysis Reference Manual. Estados Unidos, 2005.

GUSMÃO, A. D. Estudo da Interação SoloEstrutura e Sua Influência em Recalques de Edificações. São Carlos, 1990. Dissertação (Mestrado em Engenharia Civil) - Escola de Engenharia, Universidade Federal do Rio de Janeiro, Rio de Janeiro, 1990.

PORTO, T. B. Estudo da Interação de Paredes de Alvenaria Estrutural Com a Estrutura de Fundação. Belo Horizonte, 2010. Dissertação (Mestrado em Engeharia Civil) - Escola de Engenharia. Universidade Federal de Minas Gerais, Belo Horizonte, 2010.

SOUZA, F. W. C. Avaliação do Penetrômetro Manual na Previsão da Capacidade de Carga de Fundações Superficiais em Solos Arenosos. Campina Grande, 2007. Dissertação (Mestrado em Engenharia Civil) - Escola de Engenharia, Universidade Federal de Campina Grande, Campina Grande, 2007. 
TURAN, A.; HINCHBERGER, S. D.; EL

NAGGAR, M. H. Seismic Soil-Structure

Interaction in Buildings on Stiff Clay With

Embedded Basement Stories. Canadian

Geotechnical Journal, v. 50, n. 8, Aug. 2013.

\section{Fernando Luiz de Bragança Ferro}

Departamento de Engenharia Civil, Centro de Ciências Exatas e Tecnologia | Universidade Federal de Sergipe | Av. Marechal Rondon, s/n, Jardim Rosa | São Cristóvão - SE - Brasil | CEP 49100-000 | Tel.: (79) 2105-6700 | E-mail: fernandoferroaju@uol.com.br

\section{Marcos Antônio de Souza Simplício}

Unidade Acadêmica de Engenharia Civil, Centro de Tecnologia e Recursos Naturais| Universidade Federal de Campina Grande | Rua Aprígio Veloso, 882, Bairro Universitário | Campina Grande - PB - Brasil | CEP 58429-140 | Tel.: (83) 2101-1153 | E-mail: mmsimplicio@uol.com.br

\section{Wayne Santos de Assis}

Centro de Tecnologia | Universidade Federal de Alagoas | Av. Lourival de Melo Mota, s/n, Cidade Universitária, Campus A. C. Simões, Tabuleiro do Martins | Maceió - AL - Brasil | CEP 57072-970 | Tel.: (82) 3214-1725 | E-mail: wayne.assis@gmail.com

\section{Edivaldo Nascimento de Carvalho}

Centro de Ciências Exatas e Tecnologia | Universidade Federal de Sergipe | Tel.: (79) 3212-6600 | E-mail: edivaldo2316@gmail.com

\section{Revista Ambiente Construído}

Associação Nacional de Tecnologia do Ambiente Construído

Av. Osvaldo Aranha, $99-3^{\circ}$ andar, Centro

Porto Alegre - RS - Brasil

CEP $90035-190$

Telefone: +55 (51) 3308-4084

Fax: +55 (51) 3308-4054

www.seer.ufrgs.br/ambienteconstruido

E-mail: ambienteconstruido@ufrgs.br 